\title{
Effects of surface roughness on CMAS corrosion behavior for thermal barrier coating applications
}

\author{
Lei GUO ${ }^{a, b, *}$, Guang $\mathrm{LI}^{a}$, Zhilin GAN ${ }^{a}$ \\ ${ }^{a}$ School of Materials Science and Engineering, Tianjin University, Tianjin 300072, China \\ ${ }^{b}$ Tianjin Key Laboratory of Advanced Joining Technology, Key Lab of Advanced Ceramics \\ and Machining Technology of Ministry of Education, Tianjin 300072, China
}

Received: August 16, 2020; Revised: December 17, 2020; Accepted: December 22, 2020

(c) The Author(s) 2020.

\begin{abstract}
Calcium-magnesium-alumina-silicate (CMAS) corrosion is an important cause for thermal barrier coating (TBC) failure, which has attracted increased attentions. In this study, some thermal barrier coating (TBC) materials including YSZ (yttria partially stabilized zirconia), $\mathrm{GdPO}_{4}$, and $\mathrm{LaPO}_{4}$ were prepared into bulks, and the effects of their surface roughness on wettability and spreading characteristics of molten CMAS were investigated. As-fabricated and polished bulks with different surface roughness were exposed to CMAS corrosion at $1250{ }^{\circ} \mathrm{C}$ for 1 and $4 \mathrm{~h}$, following by macro and micro observations. Results revealed that compared with the as-fabricated bulks, molten CMAS on the polished samples had lower wettability and a smaller spreading area, mainly attributable to the reduced capillary force to drive the melt spreading. Meanwhile, $\mathrm{GdPO}_{4}$ and $\mathrm{LaPO}_{4}$ bulks exhibited lower CMAS wettability than YSZ bulk. It is thus considered that reducing the surface roughness is beneficial to CMAS corrosion resistance of TBCs.
\end{abstract}

Keywords: thermal barrier coating (TBC); calcium-magnesium-alumina-silicate (CMAS); surface roughness; wetting; spreading

\section{Introduction}

Thermal barrier coating (TBC) is one of the core technologies of modern aero engines. With the development of aviation industry, the thrust-weight ratio of aero engines continues to increase, leading to an increase in the operating temperature of TBCs [1-4]. And the most commonly used ceramic top coat material for TBCs is yttria partially stabilized zirconia (YSZ) [2]. In actual operating environments, fine particulate matters in desert or from volcanic eruption are ingested into engines,

* Corresponding author.

E-mail: glei028@tju.edu.cn which could be transformed into molten glass at high temperatures. Although the geographic location and operating conditions of aero engines are different, the composition of glassy substances is basically close, mainly consisting of $\mathrm{CaO}, \mathrm{MgO}, \mathrm{Al}_{2} \mathrm{O}_{3}, \mathrm{SiO}_{2}$ (CMAS) [5-8].

Traditional YSZ materials have difficulties in resisting to CMAS attack, so scientists and technicians are trying to develop new types of TBC materials, and some studies have shown that the rare earth phosphates with monazite structure exhibit excellent resistance to CMAS corrosion [9-12]. Guo et al. prepared a series of rare earth phosphates $\mathrm{LnPO}_{4}\left(\mathrm{NdPO}_{4}, \mathrm{SmPO}_{4}\right.$, and $\mathrm{GdPO}_{4}$ ) bulks and studied the penetration depth of CMAS in the bulks at $1250{ }^{\circ} \mathrm{C}$, comparing it with the 
CMAS corrosion resistance of YSZ bulks. The results show that the three rare earth phosphates have better CMAS corrosion resistance than YSZ, among which CMAS has the smallest penetration depth in $\mathrm{GdPO}_{4}$ bulk, indicating that $\mathrm{GdPO}_{4}$ has the best CMAS corrosion resistance [11].

During aero engine operation, CMAS is deposited on TBC surface firstly, and then melts, wets, and infiltrates into the coating at high temperatures, which causes phase transformation of the coating and also mdestroys the coating microstructure, resulting in premature failure of TBCs [2,13-15]. In the corrosion process of CMAS to TBCs, the wetting of molten CMAS plays an important role, which needs special attention and study.

Wetting is a phenomenon of liquid diffusion on solid surface caused by the interaction between molecules. The ability of liquid diffusion on solid surface is called wettability [16]. The definition of contact angle $(\theta)$ is as follows: through the three-phase contact point, make a tangent to the liquid-gas interface, and the angle between the tangent line of liquid-gas interface and solid-liquid interface is the contact angle. Contact angle $(\theta)$ is used to characterize the wettability: when $0^{\circ}<\theta<90^{\circ}$, solid surface is hydrophilic; when $90^{\circ}<\theta<$ $180^{\circ}$, solid surface is hydrophobic. In particular, when $\theta=0^{\circ}$, it is called complete wetting, and with $\theta=180^{\circ}$, it is called completely non-wetting; when the liquid is in equilibrium on the solid surface, the contact angle is called the equilibrium wetting angle [16-18]. Factors affecting wetting include liquid surface tension, solid surface energy, and surface roughness.

The wetting behavior of CMAS on YSZ coating has been studied before. Zhang et al. [19] investigated the wetting and infiltration behavior of CMAS towards YSZ coating deposited by plasma spray physical vapor. The results showed that CMAS undergoes a short-time spread-out process, which is mainly attributed to the suddenly decreased surface tension of molten CMAS. Kang et al. [20] tailored three coatings with different surface microstructures: polished, as-sprayed, and femtosecond laser ablated, and studied the wetting behavior of molten CMAS on them. Results showed that compared with the other two coatings, the femtosecond laser ablated coating exhibits a slight decrease in contact angle, contact diameter, droplet height, and droplet volume. Some scholars studied the wetting behavior of CMAS on YSZ coating through first-principles calculation, and indicated that oxygen ion distribution on the coating surface is a key factor affecting the wettability and the corrosion behavior of CMAS to the coating $[21,22]$. The wetting behavior of CMAS on newly developed TBC material has also been studied. Qu et al. [23] indicated that CMAS has a larger contact angle and a slower spreading speed on the $\mathrm{LaTi}_{2} \mathrm{Al}_{9} \mathrm{O}_{19}$ bulk than that on the YSZ bulk at the same condition.

As mentioned above, CMAS corrosion behavior of TBC materials or coatings has been studied by considering the wetting behavior of molten CMAS, but the influence of surface characteristics (such as roughness) on molten CMAS wettability and spreading characteristics is rarely involved. According to the study of Wenzel [24], the equilibrium wetting angle of liquid on rough surface can be expressed as follows:

$$
\cos \theta_{\mathrm{r}}=W_{\mathrm{r}} \cos \theta_{0}
$$

where $\theta_{\mathrm{r}}$ is the equilibrium wetting angle of the liquid on the rough surface, $W_{\mathrm{r}}$ is the ratio of the actual surface area to the nominal surface area, and $\theta_{0}$ is the equilibrium wetting angle of the liquid on the smooth surface. Therefore, the surface roughness plays an importance role in the wettability and spreading behavior of molten CMAS on TBCs. In this study, some TBC materials such as $\mathrm{YSZ}, \mathrm{GdPO}_{4}$, and $\mathrm{LaPO}_{4}$ are prepared into bulks with various roughnesses, and the wettability and spreading characteristics of molten CMAS on these bulks are investigated, aiming to clarifying the effect of the surface roughness on the CMAS corrosion behavior for TBC applications.

\section{Experimental procedure}

\section{1 Preparation of $\mathrm{YSZ}, \mathrm{GdPO}_{4}$, and $\mathrm{LaPO}_{4}$ powders}

All the powders in this experiment were synthesized by a chemical co-precipitation and calcination method. The synthesis process of YSZ $\left(7 \mathrm{wt} \% \mathrm{Y}_{2} \mathrm{O}_{3}\right.$ doped $\mathrm{ZrO}_{2}$ ) powders was as follows: the appropriate quantity of $\mathrm{Y}_{2} \mathrm{O}_{3}$ powders and $\mathrm{ZrOCl}_{2} \cdot 8 \mathrm{H}_{2} \mathrm{O}$ were dissolved in nitric acid and deionized water, respectively. The two solutions were mixed and added drop by drop to excess ammonia water $(\mathrm{pH}>12)$ to obtain gel-like precipitate. The obtained precipitate was washed with deionized water and absolute ethanol, and filtered until the filtrate was clear $(\mathrm{pH} \approx 7)$. Then the filter cake was dried at $80{ }^{\circ} \mathrm{C}$ for $12 \mathrm{~h}$, calcined at $900{ }^{\circ} \mathrm{C}$ for $4 \mathrm{~h}$, and ground and screened to obtain YSZ powders. $\mathrm{LaPO}_{4}$ powder synthesis processes are similar to YSZ powders: $\mathrm{La}_{2} \mathrm{O}_{3}$ was dissolved in nitric acid and then mixed with 
$\left(\mathrm{NH}_{4}\right)_{2} \mathrm{HPO}_{4}$, followed by adding drop by drop to excess ammonia water $(\mathrm{pH}>12)$ through three-necked bottle, until the reaction was finished with gel-like precipitate. The obtained precipitate was washed with deionized water and absolute ethanol, and filtered until the filtrate was clear $(\mathrm{pH} \approx 7)$. $\mathrm{GdPO}_{4}$ powder synthesis processes are as follows: $\mathrm{Gd}_{2} \mathrm{O}_{3}$ and excess $\mathrm{H}_{3} \mathrm{PO}_{4}$ were mixed and stirred until the reaction was completed, and the suspension was washed with deionized water and absolute ethanol, and filtered until the filtrate was clear. Then the filter cakes $\left(\mathrm{GdPO}_{4}\right.$ and $\left.\mathrm{LaPO}_{4}\right)$ were dried at $80{ }^{\circ} \mathrm{C}$ for $12 \mathrm{~h}$, calcined at $900{ }^{\circ} \mathrm{C}$ for $4 \mathrm{~h}$, and ground and sieved to obtain $\mathrm{GdPO}_{4}$ and $\mathrm{LaPO}_{4}$ powders.

\section{2 Preparation of $\mathrm{YSZ}, \mathrm{GdPO}_{4}$, and $\mathrm{LaPO}_{4}$ bulks}

The prepared powders were put into the compression mold and pressed. The pressure was set at $150 \mathrm{MPa}$, and the diameter of the bulks was about $2 \mathrm{~cm}$. Then, the pressed YSZ bulks were placed in a muffle furnace and sintered at $1300{ }^{\circ} \mathrm{C}$ for $10 \mathrm{~h}$, the pressed $\mathrm{GdPO}_{4}$ and $\mathrm{LaPO}_{4}$ bulks were sintered at $1500{ }^{\circ} \mathrm{C}$ for $10 \mathrm{~h}$, and the diameter of the bulks was about $1.8 \mathrm{~cm}$ after sintering. Each type of bulk was processed into two states: the as-fabricated and polished. The polished pieces were manually ground with 400\#, 800\#, 1200\#, $1500 \#$, and $3000 \#$ silicon carbide sandpaper (Eagle brand), followed by polishing on a rotary polishing machine (MP-2B) with velvet polishing cloth for 5-10 min. After the above steps, the polished bulks of each material were obtained, and the standard of manual grinding process is that the grinded surface scratch completely covers the surface scratch grinded before.

\section{3 Preparation of CMAS glass}

In this study, the composition of CMAS was $33 \mathrm{CaO}$ $9 \mathrm{MgO}-13 \mathrm{Al}_{2} \mathrm{O}_{3}-45 \mathrm{SiO}_{2}(\mathrm{~mol} \%)$, which was determined by referring to the chemical composition of the glass deposit on the surface of the blade [8]. The raw materials were carefully weighed in the appropriate molar ratio and suspended in deionized water, followed by planetary ball milling (QM-3SP4) for $6 \mathrm{~h}$ at a speed of $400 \mathrm{rpm}$ until the raw materials were mixed sufficiently. Then the resultant suspension was dried at $200{ }^{\circ} \mathrm{C}$ for $10 \mathrm{~h}$, dehydrated at $800{ }^{\circ} \mathrm{C}$ for $6 \mathrm{~h}$, and kept at $1550{ }^{\circ} \mathrm{C}$ for $2 \mathrm{~h}$. After that, the CMAS glass was obtained by pouring the molten CMAS onto a copper plate in water, in order to ensure the purity of CMAS glass; the bottom of CMAS glass, which contacted with copper plate directly, was removed by grinding. At last, CMAS powders were obtained by grinding and sieving.

To evenly cover the CMAS powders onto bulk surface, a 400\# sieve and a paper sheet with a hole (diameter of the hole is $0.8 \mathrm{~cm}$ ) were used. Firstly, a certain amount of CMAS was carefully weighed by an analytical balance and put into a $400 \#$ sieve, and the bulk was covered by the paper sheet, followed by placing the sieve on the top of the bulk and shaking the sieve at a constant speed until the CMAS powder density on bulk reaches to $10 \mathrm{mg} / \mathrm{cm}^{2}$. The bulks with CMAS deposits were heat-treated in a box electric furnace $\left(\mathrm{SX}-1600{ }^{\circ} \mathrm{C}\right)$ at $1250{ }^{\circ} \mathrm{C}$ for 1 and $4 \mathrm{~h}$.

\section{4 Preparation of cross sections}

The preparation process of polished cross sections was as follows: the sample corroded by CMAS was put into a mold after being fixed by the fixture, the prepared curing solution (mass ratio of resin : curing agent $=2: 1$ ) was evenly poured into the mold, and then the pattern inlaid with samples was obtained after condensing for $2 \mathrm{~h}$. The piece inlaid with sample was manually ground with 400\#, 800\#, 1200\#, 1500\#, and 3000\# silicon carbide sandpaper (Eagle brand), followed by polishing on a rotary polishing machine (MP-2B) with velvet polishing cloth. After the above steps, the polished cross section of each material was obtained.

\section{5 Characterizations}

In the experiment, the surface roughness was measured by an atomic force microscope (AFM; afm5500, AGILENT, USA) using Silicon AFM Probe (Tap190-G Budget Sensors) whose force constant and resonant frequency are $48 \mathrm{~N} / \mathrm{m}$ and $190 \mathrm{kHz}$, respectively. The AFM worked at a horizontal scanning length and a scanning rate of 0.7 lines/s under the normal temperature and pressure. And the X-ray diffractometer (XRD; Bruker D8 Advanced, Germany) equipped with $\mathrm{Cu} \mathrm{K} \alpha$ radiation was employed in characterizing the phase composition of the materials and reaction products. The scanning range was $10^{\circ}-80^{\circ}$ and the scanning rate was $0.2\left(^{\circ}\right) / \mathrm{s}$. After the scanning, the XRD patterns were recorded. Scanning electron microscopy (SEM; TDCLS4800, Hitachi Ltd., Japan) equipped with energy dispersive spectrometer (EDS; IE 350) was used to observe the surface morphology and cross-section microstructure. 


\section{Results and discussion}

AFM images of the surface of $\mathrm{GdPO}_{4}$ bulks are shown in Fig. 1. Comparing the 3D surface topography and 2D height map of polished bulk (Fig. 1(a)) and that of as-fabricated bulk (Fig. 1(b)), it can be found that the surface roughness difference between the two bulks is obvious. The surface state of YSZ and $\mathrm{LaPO}_{4}$ bulks is similar to that of $\mathrm{GdPO}_{4}$, so they are not repeated. According to the measurement results, the surface roughness of polished $\mathrm{YSZ}, \mathrm{GdPO}_{4}$, and $\mathrm{LaPO}_{4}$ bulks is $0.14,0.18$, and $0.17 \mu \mathrm{m}$, respectively; and that of as-fabricated YSZ, $\mathrm{GdPO}_{4}$, and $\mathrm{LaPO}_{4}$ bulks is 1.16 , 0.98 , and $1.11 \mu \mathrm{m}$, respectively. That is to say, the roughness of polished bulk is $0.14-0.18 \mu \mathrm{m}$ approximately, and that of as-fabricated bulk is about $0.98-$ $1.12 \mu \mathrm{m}$.

\section{1 Effects of roughness on wetting behavior of molten CMAS on YSZ bulks}

Figure 2 shows macroscopic morphologies of polished and as-fabricated YSZ bulks exposed to CMAS at $1250{ }^{\circ} \mathrm{C}$ for 1 and $4 \mathrm{~h}$. After heat treatment at $1250{ }^{\circ} \mathrm{C}$ for $1 \mathrm{~h}$, obvious residual CMAS glass can be observed on the surfaces of the two bulks, and the spreading area of CMAS on the polished bulk (the area highlighted by a red line in Fig. 2(a)) is smaller than that on the as-fabricated bulk (the area highlighted by a black line in Fig. 2(b)). It could be inferred that the wettability of molten CMAS on the polished surface is lower. To verify the inference, the cross-section images of CMAS/YSZ bulks were collected, and the contact angles were measured in the following section. As shown in Figs. 2(c) and 2(d), little residual CMAS glass could be observed on surfaces of both polished and as-fabricated YSZ bulk after heat treatment for $4 \mathrm{~h}$, indicating that the penetration of molten CMAS into the YSZ bulk increases with time.

Regions A and B in Fig. 2(a) are observed by SEM at a higher magnification, and their images are shown in Figs. 3(a) and 3(b), respectively. As shown in Fig. 3(a), spherical monoclinic (m) $\mathrm{ZrO}_{2}$ and residual CMAS glass can be clearly observed at the spreading edge of molten CMAS after heat treatment at $1250{ }^{\circ} \mathrm{C}$ for $1 \mathrm{~h}$, which means that the phase transformation of YSZ in this region has occurred due to CMAS corrosion. The results of element analysis of the marked areas 1 and 2 in Fig. 3(a) are also shown in the figure, from which it can be found that besides $\mathrm{Zr}$ and $\mathrm{Y}$ elements, $\mathrm{Ca}$ element is also contained in region of the spherical $\mathrm{m}-\mathrm{ZrO}_{2}$. It is indicated that the dissolution of YSZ may occur in the process of CMAS corroding YSZ. In Fig. 3(b), the surface morphology is still compact without spherical $\mathrm{m}-\mathrm{ZrO}_{2}$ and residual CMAS, suggesting that CMAS corrosion only occurs in the center of YSZ bulk.
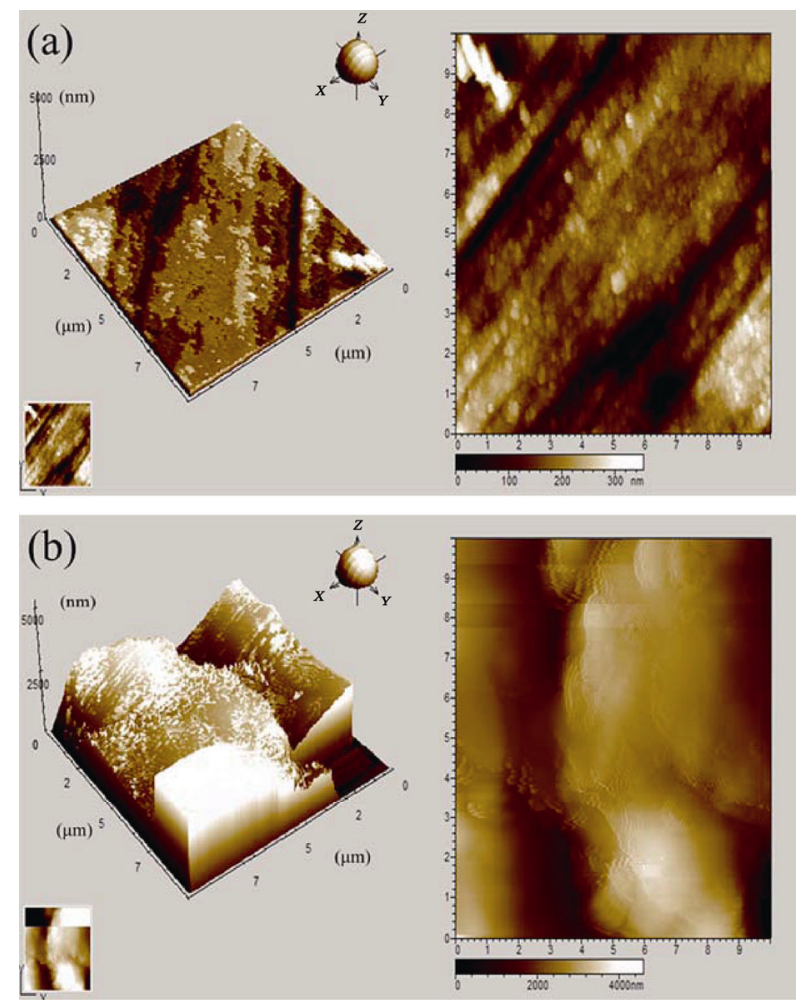

Fig. 1 AFM images of the surfaces of polished (a) and as-fabricated (b) $\mathrm{GdPO}_{4}$ bulks.
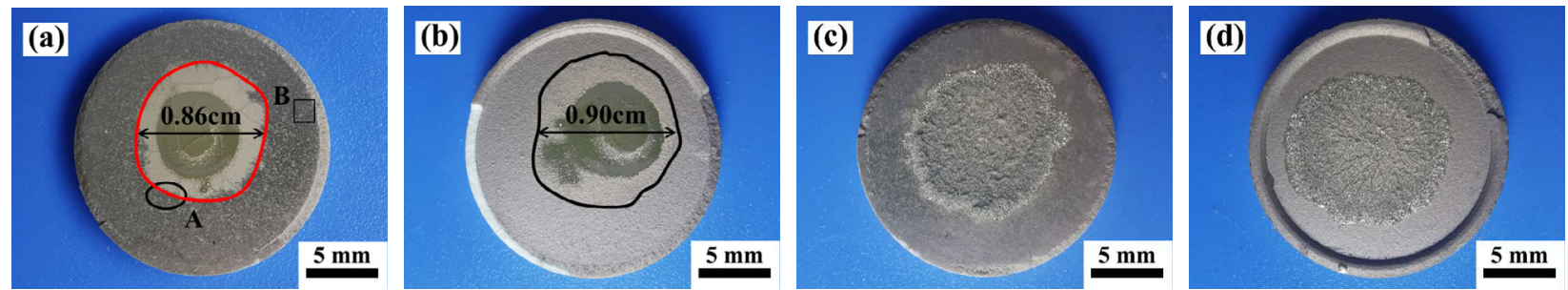

Fig. 2 Macroscopic morphologies of polished ( $a, c)$ and as-fabricated (b, d) YSZ bulks exposed to CMAS at $1250{ }^{\circ} \mathrm{C}$ for $1 \mathrm{~h}(\mathrm{a}, \mathrm{b})$ and $4 \mathrm{~h}(\mathrm{c}, \mathrm{d})$. 

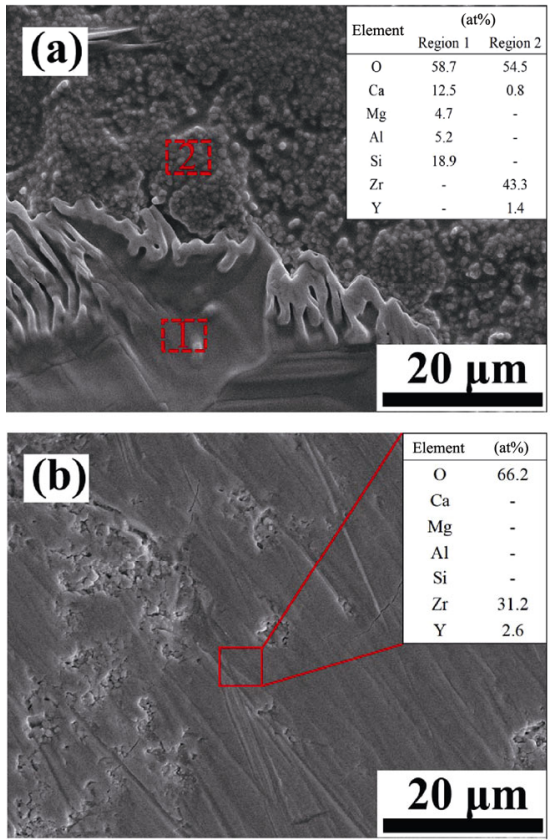

Fig. 3 SEM images of CMAS/polished YSZ bulk: (a) and (b) corresponding to regions A and B in Fig. 2(a), respectively.

Many researchers have reported that YSZ is unable to resist corrosion by CMAS, and the mechanisms are complex [6-8]. One of the main reasons for the failure of YSZ caused by CMAS is the transformation of $\mathrm{ZrO}_{2}$ from metastable tetragonal phase ( $\mathrm{t}$ '- $\left.\mathrm{ZrO}_{2}\right)$ to $\mathrm{m}-\mathrm{ZrO}_{2}$ induced by CMAS [8], which could be explained by a dissolution and precipitation mechanism [8,25,26]. At $1250{ }^{\circ} \mathrm{C}$, CMAS melts and wets the YSZ surface firstly, and then $\mathrm{ZrO}_{2}$ and $\mathrm{Y}_{2} \mathrm{O}_{3}$ dissolve in the CMAS at interface. Because the amount of $\mathrm{ZrO}_{2}$ is much more abundant, $\mathrm{ZrO}_{2}$ precipitates first from the molten CMAS. Since the solubility of $\mathrm{Y}_{2} \mathrm{O}_{3}$ in molten CMAS is high, the precipitated crystals contain very few $\mathrm{Y}_{2} \mathrm{O}_{3}$, which results in the formation of $\mathrm{m}-\mathrm{ZrO}_{2}$ in the cooling process on account of the lack of sufficient amounts of stabilizers $\left(\mathrm{Y}_{2} \mathrm{O}_{3}\right)$. In this experiment, as mentioned above, a lot of spherical $\mathrm{m}-\mathrm{ZrO}_{2}$ particles are observed in the CMAS corrosion area, and $\mathrm{Ca}$ element is contained in the region of $\mathrm{m}-\mathrm{ZrO}_{2}$, which makes this mechanism confirmed.

The cross-section microstructures of polished and as-fabricated YSZ bulks after heat treatment at $1250{ }^{\circ} \mathrm{C}$ for $1 \mathrm{~h}$ are shown in Fig. 4. According to the definition of contact angle $[16,17]$, the contact angle is measured by the direct measurement method, that is, with the help of SEM, the cross-section microstructure is captured, a tangent to the liquid-gas interface is made through the three-phase contact point, and the angle between the tangent line of liquid-gas interface and solid-liquid interface is measured directly. When the molten CMAS is in equilibrium on the surface of the YSZ bulk, the contact angle does not change any more. The final state after slow cooling is equal to the equilibrium state, that is to say, the contact angle of the final state is also the equilibrium wetting angle. As shown in Figs. 4(b) and 4(d), the contact angles of the CMAS/polished YSZ bulk and the CMAS/as-fabricated YSZ bulk are $10.1^{\circ}$ $\left(\theta_{1}\right)$ and $7.8^{\circ}\left(\theta_{2}\right)$, respectively. The EDS element maps corresponding to Fig. 4(d) are shown in Fig. 4(e), where $\mathrm{Ca}, \mathrm{Mg}, \mathrm{Al}, \mathrm{Si}$ elements are observed in the matrix of YSZ, indicating that the YSZ bulk has been corroded by CMAS in the CMAS wetting area after heat treatment at $1250{ }^{\circ} \mathrm{C}$ for $1 \mathrm{~h}$.

According to the research of Yost [27,28], a rough surface can be regarded as a three-dimensional network structure composed of interconnected micro V-grooves. When the liquid flows in these micro V-grooves, there is additional capillary force to drive the liquid spreading. Therefore, the greater the roughness, the better the
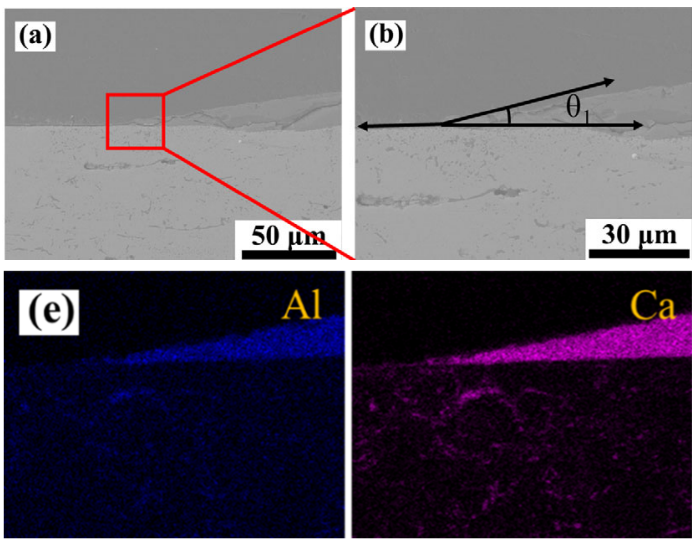
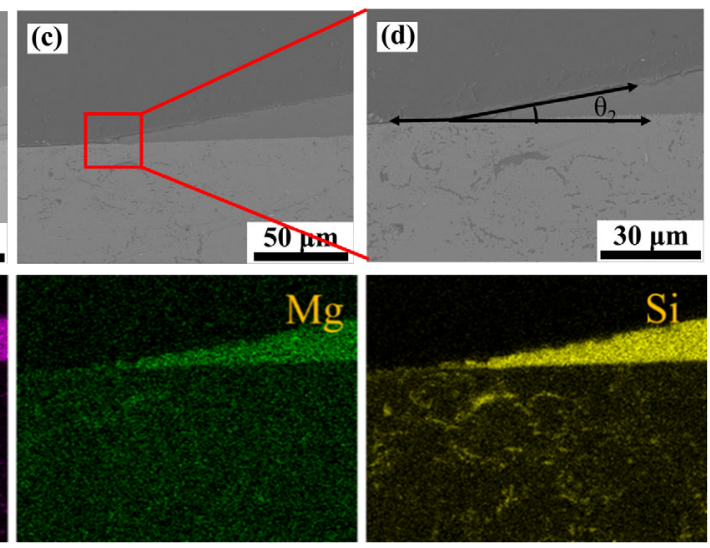

Fig. 4 Cross-section microstructures of polished ( $a, b)$ and as-fabricated (c, d) YSZ bulks exposed to CMAS at $1250{ }^{\circ} \mathrm{C}$ for $1 \mathrm{~h}$; (e) EDS element maps corresponding to (d). 
wetting. The polished YSZ pellet lacks this threedimensional structure composed of micro V-grooves, which makes it more difficult for the molten CMAS to wet its surface.

Besides, on the basis of Wenzel theory [24] about the influence of roughness on liquid wettability, a rough surface increases the actual surface area of liquid wetting. It can be concluded that if the wettability is $\operatorname{good}\left(\theta_{0}<90^{\circ}\right)$ on a smooth surface, it will be better on a rough surface; if the wettability is bad $\left(\theta_{0}>90^{\circ}\right)$ on a smooth surface, the wettability on a rough surface will be worse. The wetting angle of molten CMAS on the polished YSZ bulk surfaces is less than $90^{\circ}$; therefore, according to the Wenzel law, the wetting angle of molten CMAS on as-fabricated bulks would be smaller. As it has been shown in Fig. 4, the wetting angle of molten CMAS on the as-fabricated YSZ bulk is $7.8^{\circ}$, lower than $10.1^{\circ}$, which is consistent with the Wenzel law.

\section{2 Effects of surface roughness on wetting behavior of molten $\mathrm{CMAS}$ on $\mathrm{GdPO}_{4}$ and $\mathrm{LaPO}_{4}$ bulks}

Figure 5 shows the macroscopic morphologies of polished and as-fabricated $\mathrm{GdPO}_{4}$ bulks with CMAS deposits at $1250{ }^{\circ} \mathrm{C}$ for 1 and 4 h. Comparing Figs. 5(a) and 5(b), it is observed that the residual CMAS on the polished bulk is more than that on the as-fabricated bulk after heat treatment at $1250{ }^{\circ} \mathrm{C}$ for $1 \mathrm{~h}$. The difference in the residual CMAS on the polished and as-fabricated $\mathrm{GdPO}_{4}$ bulk shown in Figs. 5(a) and 5(b) is so significant that the contact angle difference between CMAS/polished $\mathrm{GdPO}_{4}$ bulk and CMAS/as-fabricated $\mathrm{GdPO}_{4}$ bulk could also be easily inferred, and cross section images are also collected in the following discussion to verify the inference. With the extension of heat treatment time to $4 \mathrm{~h}$ (Figs. 5(c) and 5(d)), the residual CMAS on the surfaces of both bulks significantly decreases, and the residual melt is hardly observed on the surface of the as-fabricated bulk. Furthermore, comparing Fig. 5 to Fig. 2, it is obvious that residual CMAS on the surface of the $\mathrm{GdPO}_{4}$ bulk surface is far more than that on the YSZ bulk for the same heat treatment time, meaning that $\mathrm{GdPO}_{4}$ has a higher resistance to CMAS penetration, which could be confirmed in the next discussion.

Figures 6(a) and 6(b) are SEM images corresponding to regions C and D in Figs. 5(a) and 5(b), respectively. It is clear that residual CMAS and short rod or block
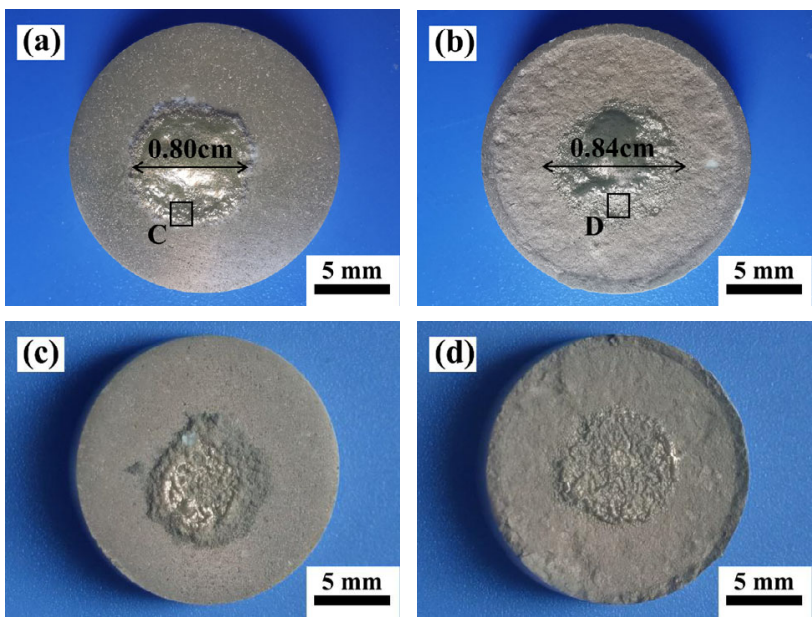

Fig. 5 Macroscopic morphologies of polished (a, c) and as-fabricated (b, d) $\mathrm{GdPO}_{4}$ bulks exposed to CMAS at $1250{ }^{\circ} \mathrm{C}$ for $1 \mathrm{~h}(\mathrm{a}, \mathrm{b})$ and $4 \mathrm{~h}(\mathrm{c}, \mathrm{d})$.
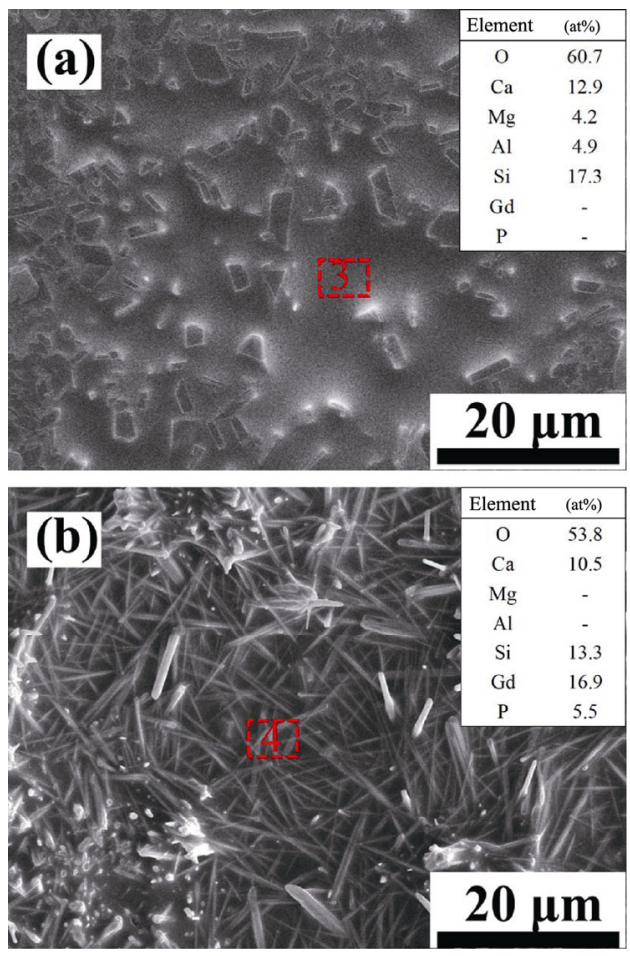

Fig. 6 Surface SEM images of $\mathrm{GdPO}_{4}$ bulks exposed to CMAS at $1250{ }^{\circ} \mathrm{C}$ for $1 \mathrm{~h}$. (a) and (b) shows the regions of $\mathrm{C}$ and $\mathrm{D}$ highlighted by black squares in Fig. 5, respectively. EDS results of regions 1 and 2 are present in the table.

crystals can be observed at the spreading edge of molten CMAS on the surface of the polished $\mathrm{GdPO}_{4}$ bulk, as shown in Fig. 6(a). The precise element composition of these short rod or block crystals cannot be obtained by EDS analysis, making it hard to determine what they are, while the element ratio of region 3 in Fig. 6(a) is close to the composition of 
CMAS, suggesting that the edge of CMAS/polished $\mathrm{GdPO}_{4}$ bulk is covered with molten CMAS. However, acicular crystals (Fig. 6(b)) are observed at the edge of CMAS/as-fabricated $\mathrm{GdPO}_{4}$ bulk, and the EDS analysis of region 4 shows that the acicular crystals contain $\mathrm{Ca}, \mathrm{Gd}, \mathrm{P}, \mathrm{Si}, \mathrm{O}$ elements, so the XRD analysis of CMAS/as-fabricated $\mathrm{GdPO}_{4}$ bulk was carried out and the pattern is shown in Fig. 7. The diffraction peaks of $\mathrm{CaAl}_{2} \mathrm{Si}_{2} \mathrm{O}_{8}$ (PDF\#41-1486), $\mathrm{MgAl}_{2} \mathrm{O}_{4}$ (PDF\#47-0254), and P-Si apatite phases are detected. Combing the EDS result and the XRD pattern, it can be determined that the acicular crystals are $\mathrm{P}-\mathrm{Si}$ apatite phase, which is consistent with previous research $[10,12,29,30]$.

The main formation mechanism of $\mathrm{P}-\mathrm{Si}$ apatite phase could be due to dissolution re-precipitation [31]. When the surface temperature exceeds $1250{ }^{\circ} \mathrm{C}$, CMAS begins to melt, wet, and spread on the bulk surface. At the same time, $\mathrm{GdPO}_{4}$ is dissolved in the molten CMAS, causing $\mathrm{Gd}$ and $\mathrm{P}$ elements to diffuse into CMAS. When the content of Gd and P in CMAS reaches to the critical value, $\mathrm{P}-\mathrm{Si}$ apatite precipitates into a crystalline form. Because the diffusion rate of Gd and $\mathrm{P}$ in molten CMAS is different, the distribution of $\mathrm{Gd}$ and $\mathrm{P}$ in molten CMAS is inhomogeneous, which causes different atomic ratios of $\mathrm{Gd}$ and $\mathrm{P}$ in different regions, so non-stoichiometric $\mathrm{P}-\mathrm{Si}$ apatite is formed.

The microstructure of polished and as-fabricated $\mathrm{GdPO}_{4}$ bulks after heat treatment at $1250{ }^{\circ} \mathrm{C}$ for $1 \mathrm{~h}$ is shown in Figs. 8(a) and 8(b), respectively. The contact angles of $\mathrm{CMAS} /$ polished $\mathrm{GdPO}_{4}$ bulk and CMAS/ as-fabricated $\mathrm{GdPO}_{4}$ bulk are directly measured according to the angle measurement method described in Section 3.1. The contact angle of CMAS/polished $\mathrm{GdPO}_{4}$ bulk $\left(\theta_{1}\right)$ is $69.6^{\circ}$, and that of CMAS/asfabricated $\mathrm{GdPO}_{4}$ bulk $\left(\theta_{2}\right)$ is $41.0^{\circ}$. The cross-section image of CMAS/as-fabricated $\mathrm{GdPO}_{4}$ at a higher magnification is shown in Fig. 8(c), from which block crystals and acicular crystals can be observed. According to the element analysis of region 5 in the figure and the XRD pattern in Fig. 7, it can be determined the block crystals are $\mathrm{CaAl}_{2} \mathrm{Si}_{2} \mathrm{O}_{8}$. As for the acicular crystals of region 6 , as mentioned above, they are $\mathrm{P}-\mathrm{Si}$ apatite phases. The map scanning is carried out for Fig. 8(b), and the results are shown in Fig. 8(d). Different from the results in Fig. 4(e), it could be seen that little CMAS has penetrated into the $\mathrm{GdPO}_{4}$ bulk, and on the basis of previous research, it is these $\mathrm{CaAl}_{2} \mathrm{Si}_{2} \mathrm{O}_{8}$ and $\mathrm{P}-\mathrm{Si}$ apatite phases that hinder the further penetration of molten CMAS [29,30].

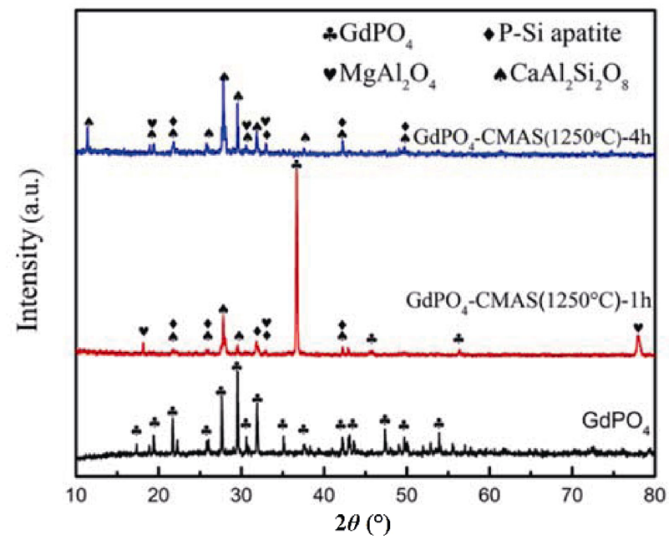

Fig. 7 XRD patterns of the $\mathrm{GdPO}_{4}$ bulk and the bulks with CMAS deposits subjected to $1250{ }^{\circ} \mathrm{C}$ for 1 and $4 \mathrm{~h}$.
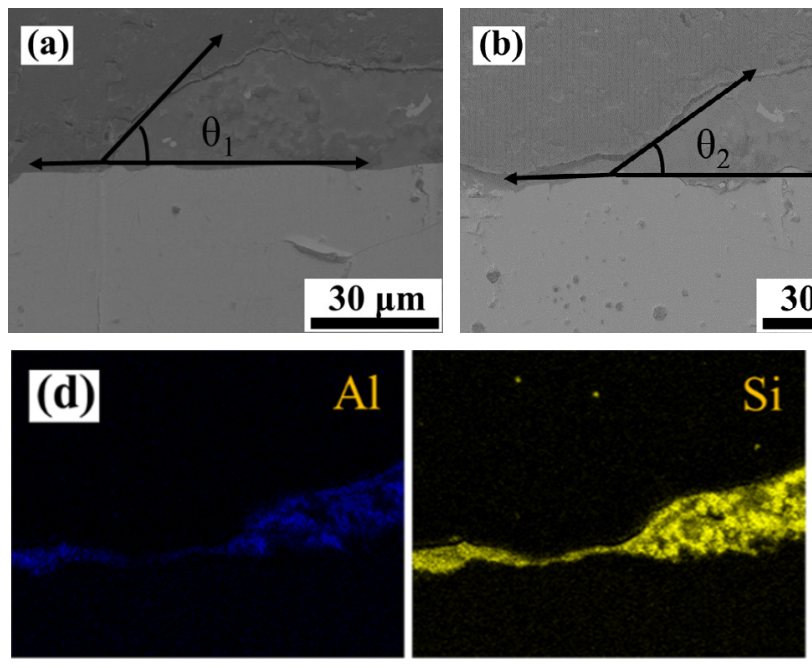

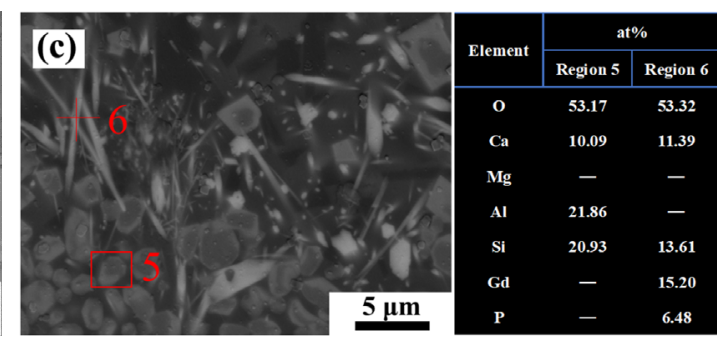

$\mathrm{P}$

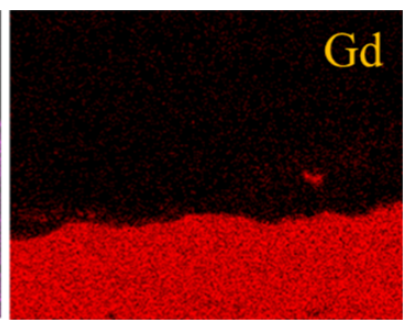

Fig. 8 Cross-section microstructures of polished (a) and as-fabricated (b) $\mathrm{GdPO}_{4}$ bulks exposed to CMAS at $1250{ }^{\circ} \mathrm{C}$ for $1 \mathrm{~h}$; (c) cross-section image of CMAS/as-fabricated $\mathrm{GdPO}_{4}$ at a higher magnification; (e) EDS element maps corresponding to (b). 

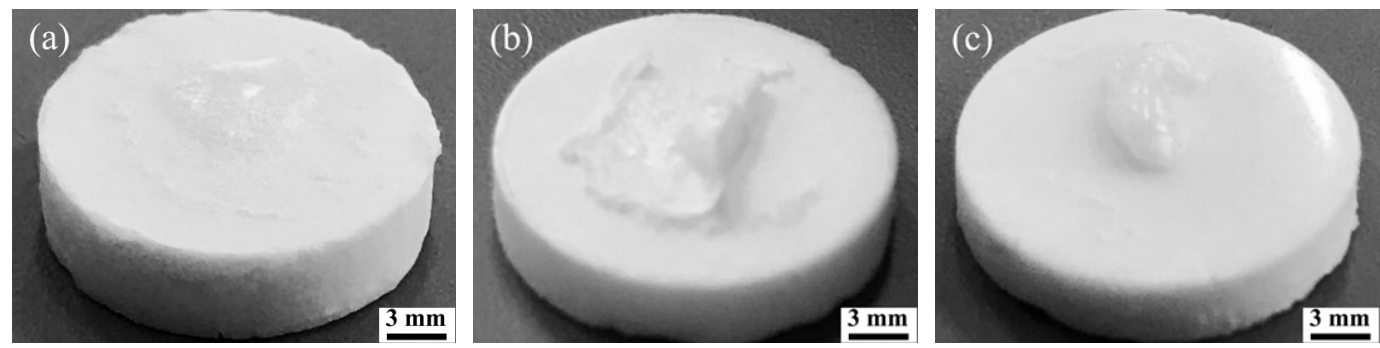

Fig. 9 Morphologies of the CMAS-covered $\mathrm{LaPO}_{4}$ bulks after heat treatment at $1250{ }^{\circ} \mathrm{C}$ : (a) as-fabricated bulk for $1 \mathrm{~h}$; (b) and (c) the polished bulks for 1 and $4 \mathrm{~h}$, respectively.

The wetting behavior of CMAS on $\mathrm{GdPO}_{4}$ is similar to that of YSZ, which shows that it is more difficult to wet the polished bulk surface. This can also be explained by the three-dimensional mesh theory of Yost [27,28] and Wenzel law [24], which has been mentioned before.

Figure 9(a) shows the macroscopic morphology of the as-fabricated $\mathrm{LaPO}_{4}$ corroded by CMAS at $1250{ }^{\circ} \mathrm{C}$ for $1 \mathrm{~h}$. It can be seen that the molten CMAS has spread on the surface. Figures 9(b) and 9(c) show the macroscopic morphologies of the polished $\mathrm{LaPO}_{4}$ bulk after heat treatment at $1250{ }^{\circ} \mathrm{C}$ for 1 and $4 \mathrm{~h}$, respectively. As shown in Figs. 9(a) and 9(b), in the same heat treatment time $(1 \mathrm{~h})$, CMAS spreads on the asfabricated pellet, but agglomerates at the center of the polished one. Comparing Figs. 9(b) and 9(c), it can be found that with the extension of heat duration to $4 \mathrm{~h}$, the gathered CMAS at the center has spread to some extent.

The microstructure of the as-fabricated $\mathrm{LaPO}_{4}$ bulk after heat treatment at $1250{ }^{\circ} \mathrm{C}$ for $1 \mathrm{~h}$ is shown in Figs. 10(a) and 10(b). According to the angle measurement method described in Section 3.1, the contact angle of CMAS/as-fabricated $\mathrm{LaPO}_{4}$ bulk $\left(\theta_{1}\right)$ is measured as $28.6^{\circ}$, which is also greater than that of CMAS/asfabricated YSZ bulk. The element maps corresponding to Fig. 10(a) are shown in Fig. 10(c), where it could be seen that CMAS has not completely penetrated into the $\mathrm{LaPO}_{4}$ bulk. Similarly to $\mathrm{GdPO}_{4}$, that is also attributed to the hindrance of $\mathrm{CaAl}_{2} \mathrm{Si}_{2} \mathrm{O}_{8}$ and $\mathrm{P}-\mathrm{Si}$ apatite $[9,29,30]$.

The wettability of CMAS on the surfaces of YSZ bulk and rare earth phosphates with monazite structure $\left(\mathrm{LaPO}_{4}, \mathrm{GdPO}_{4}\right)$ bulk is compared. As shown in Fig. 4, Fig. 8, and Fig. 10, the contact angle of CMAS/YSZ is smaller than that of CMAS/ $\mathrm{GdPO}_{4}$ both on polished and as-fabricated bulk surfaces, and the contact angle of CMAS/as-fabricated YSZ bulk is also smaller than that of CMAS/as-fabricated $\mathrm{LaPO}_{4}$ bulk. The reason for the difference is the difference in the material surface energy. Under the same solid surface roughness, the greater the surface energy, the easier the solid would be wetted [16]. Wang et al. [32] and Li et al. [33] calculated surface energy of $\mathrm{LaPO}_{4}$ and YSZ by first principles, and the results show that the minimum surface energy of $\mathrm{LaPO}_{4}$ is $0.61 \mathrm{~J} / \mathrm{m}^{2}$ on (110) crystal face, and the minimum surface energy of YSZ is $0.75 \mathrm{~J} / \mathrm{m}^{2}$ on (010) crystal face. In other words, the surface energy of YSZ and $\mathrm{LaPO}_{4}$ bulk can be approximately 0.75 and $0.61 \mathrm{~J} / \mathrm{m}^{2}$ respectively. Although no scholar has calculated the surface energy of $\mathrm{GdPO}_{4}$ crystal surface, both $\mathrm{GdPO}_{4}$ and $\mathrm{LaPO}_{4}$ belong to rare earth phosphates with the monazite structure. Therefore, it can be reasonably inferred that the surface energy of $\mathrm{GdPO}_{4}$ is also less than that of YSZ, which can explain that the wettability of CMAS on the surface of $\mathrm{GdPO}_{4}$ bulk is lower than that on the surface of YSZ bulk.
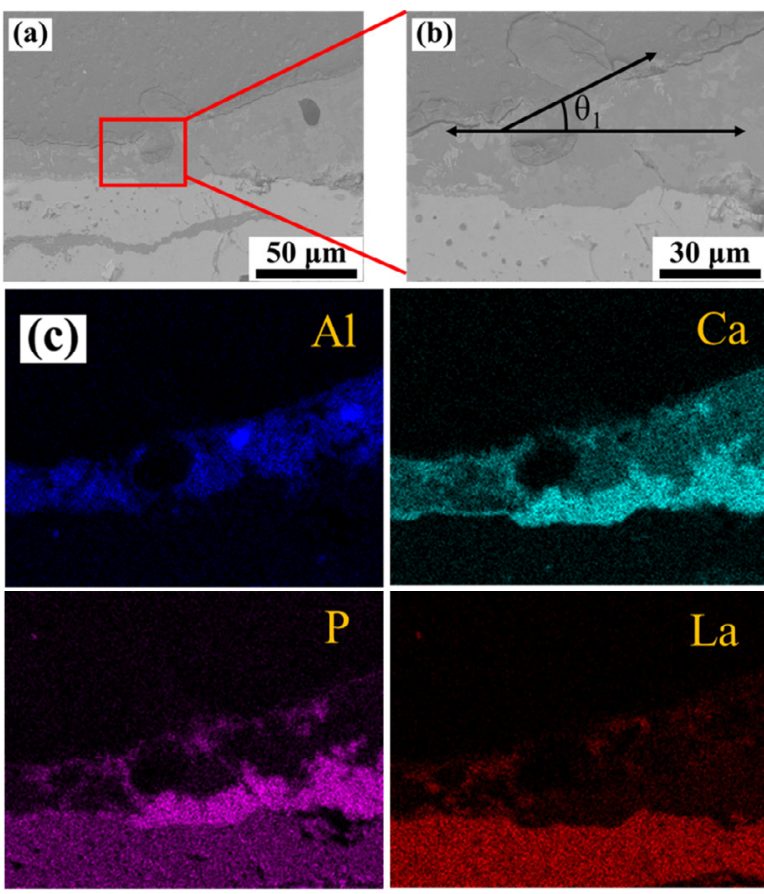

Fig. 10 Cross-section microstructures of as-fabricated (a, b) $\mathrm{LaPO}_{4}$ bulks exposed to CMAS at $1250{ }^{\circ} \mathrm{C}$ for $1 \mathrm{~h}$; (c) EDS element maps corresponding to (a). 
In this study, effects of surface roughness on CMAS wetting and spreading characteristics of $\mathrm{YSZ}, \mathrm{GdPO}_{4}$, and $\mathrm{LaPO}_{4}$ pellets are investigated, and the results indicate that surface roughness has significant influence on the CMAS corrosion behavior. First, the rough surface has a three-dimensional network structure, and secondly, it increases the actual wetting area of liquid, which can promote the wetting and diffusion of molten CMAS on the pallets. In other words, destroying this three-dimensional network structure by reducing the surface roughness can alleviate CMAS wetting and spreading. This provides a novel sight for developing methods to protect TBCs from CMAS attack, that is, designing a coating with low surface roughness.

\section{Conclusions}

In this study, TBC materials including YSZ and rare earth phosphates $\left(\mathrm{GdPO}_{4}\right.$ and $\left.\mathrm{LaPO}_{4}\right)$ are prepared into bulks, and the CMAS corrosion behavior of their as-fabricated and polished states are investigated. For YSZ and rare earth phosphates, the contact angle of the CMAS/polished bulk is larger than that of the CMAS/ as-fabricated bulk, meaning that CMAS wettability on the polished bulk is lower. The different CMAS wettability on the as-fabricated and polished bulks could be attributed to the difference in their surface textures; a rough surface could be regarded as a threedimensional network structure composed of interconnected micro V-grooves, which could provide a capillary force to drive the melt spreading, and polishing destroyed this three-dimensional structure, making it more difficult for molten CMAS to wet a surface. Under the same roughness, the wettability of CMAS on the surfaces of $\mathrm{GdPO}_{4}$ and $\mathrm{LaPO}_{4}$ bulks is lower than that on the YSZ bulk due to the lower surface energy. In summary, it is reasonable to consider that reducing the surface roughness could help to improve the CMAS corrosion resistance of TBCs.

\section{Acknowledgements}

This research is sponsored by the National Natural Science Foundation of China (Grant No. 51971156).

\section{References}

[1] Padture NP, Gell M, Jordan EH. Thermal barrier coatings for gas-turbine engine applications. Science 2002, 296: 280-284.

[2] Darolia R. Thermal barrier coatings technology: Critical review, progress update, remaining challenges and prospects. Int Mater Rev 2013, 58: 315-348.

[3] Levi CG. Emerging materials and processes for thermal barrier systems. Curr Opin Solid State Mater Sci 2004, 8: 77-91.

[4] Guo L, Xin H, Zhang Z, et al. Microstructure modification of $\mathrm{Y}_{2} \mathrm{O}_{3}$ stabilized $\mathrm{ZrO}_{2}$ thermal barrier coatings by laser glazing and the effects on the hot corrosion resistance. $J$ Adv Ceram 2020, 9: 232-242.

[5] Zhu RB, Zou JP, Mao J, et al. Fabrication and growing kinetics of highly dispersed gadolinium zirconate nanoparticles. Res Appl Mater Sci 2019, 1: 28-34.

[6] Levi CG, Hutchinson JW, Vidal-Sétif $\mathrm{MH}$, et al. Environmental degradation of thermal-barrier coatings by molten deposits. MRS Bull 2012, 37: 932-941.

[7] Mercer C, Faulhaber S, Evans AG, et al. A delamination mechanism for thermal barrier coatings subject to calciummagnesium-alumino-silicate (CMAS) infiltration. Acta Mater 2005, 53: 1029-1039.

[8] Krämer S, Yang J, Levi CG, et al. Thermochemical interaction of thermal barrier coatings with molten $\mathrm{CaO}-\mathrm{MgO}$ $\mathrm{Al}_{2} \mathrm{O}_{3}-\mathrm{SiO}_{2}$ (CMAS) deposits. J Am Ceram Soc 2006, 89: 3167-3175.

[9] Guo L, Yan Z, Yu Y, et al. CMAS resistance characteristics of $\mathrm{LaPO}_{4} / \mathrm{YSZ}$ thermal barrier coatings at $1250^{\circ} \mathrm{C}-1350^{\circ} \mathrm{C}$. Corros Sci 2019, 154: 111-122.

[10] Guo L, Yan Z, Li ZH, et al. $\mathrm{GdPO}_{4}$ as a novel candidate for thermal barrier coating applications at elevated temperatures. Surf Coat Technol 2018, 349: 400-406.

[11] Wang F, Guo L, Wang CM, et al. Calcium-magnesiumalumina-silicate (CMAS) resistance characteristics of $\mathrm{LnPO}_{4}(\mathrm{Ln}=\mathrm{Nd}, \mathrm{Sm}, \mathrm{Gd})$ thermal barrier oxides. $J$ Eur Ceram Soc 2017, 37: 289-296.

[12] Guo L, Li MZ, Cheng YX, et al. Plasma sprayed nanostructured $\mathrm{GdPO}_{4}$ thermal barrier coatings: Preparation microstructure and CMAS corrosion resistance. $J \mathrm{Am}$ Ceram Soc 2017, 100: 4209-4218.

[13] Mao WG, Wang YJ, Shi J, et al. Bending fracture behavior of freestanding $\left(\mathrm{Gd}_{0} .9 \mathrm{Yb}_{0.1}\right)_{2} \mathrm{Zr}_{2} \mathrm{O}_{7}$ coatings by using digital image correlation and FEM simulation with $3 \mathrm{D}$ geometrical reconstruction. $J A d v$ Ceram 2019, 8: 564-575.

[14] Song WJ, Lavallée Y, Wadsworth FB, et al. Wetting and spreading of molten volcanic ash in jet engines. $J$ Phys Chem Lett 2017, 8: 1878-1884.

[15] Li F, Zhou L, Liu JX, et al. High-entropy pyrochlores with low thermal conductivity for thermal barrier coating materials. J Adv Ceram 2019, 8: 576-582.

[16] Zeng Z. Interface Phenomenon. Shanghai: East China University of Science and Technology Press, 2015.

[17] Tavana H, Simon F, Grundke K, et al. Interpretation of contact angle measurements on two different fluoropolymers for the determination of solid surface tension. $J$ Colloid Interface Sci 2005, 291: 497-506. 
[18] Kumar G, Prabhu KN. Review of non-reactive and reactive wetting of liquids on surfaces. Adv Colloid Interface Sci 2007, 133: 61-89.

[19] Zhang BP, Song WJ, Guo HB. Wetting, infiltration and interaction behavior of CMAS towards columnar YSZ coatings deposited by plasma spray physical vapor. $J$ Eur Ceram Soc 2018, 38: 3564-3572.

[20] Kang YX, Bai Y, Du GQ, et al. High temperature wettability between CMAS and YSZ coating with tailored surface microstructures. Mater Lett 2018, 229: 40-43.

[21] Li BT, Chen Z, Zheng HZ, et al. Wetting mechanism of CMAS melt on YSZ surface at high temperature: Firstprinciples calculation. Appl Surf Sci 2019, 483: 811-818.

[22] Zhou PF, Li GF, Zhang YQ, et al. Infiltration mechanism of Ca-Mg-Al-silicate (CMAS) melt on yttria stabilized zirconia (YSZ) columnar crystal at high temperature: First-principles research. Appl Surf Sci 2020, 513: 145712.

[23] Qu WW, Li SS, Chen ZH, et al. Hot corrosion behavior and wettability of calcium-magnesium-alumina-silicate (CMAS) on $\mathrm{LaTi}_{2} \mathrm{Al}_{9} \mathrm{O}_{19}$ ceramic. Corros Sci 2020, 162: 108199.

[24] Wenzel RN. Resistance of solid surfaces to wetting by water. Ind Eng Chem 1936, 28: 988-994.

[25] Krause AR, Garces HF, Dwivedi G, et al. Calcia-magnesiaalumino-silicate (CMAS)-induced degradation and failure of air plasma sprayed yttria-stabilized zirconia thermal barrier coatings. Acta Mater 2016, 105: 355-366.

[26] Krause AR, Li X, Padture NP. Interaction between ceramic powder and molten calcia-magnesia-alumino-silicate (CMAS) glass, and its implication on CMAS-resistant thermal barrier coatings. Scripta Mater 2016, 112: 118-122.

[27] Yost FG, Rye RR, Mann JA Jr. Solder wetting kinetics in narrow V-grooves. Acta Mater 1997, 45: 5337-5345.

[28] Rye RR, Mann JA, Yost FG. The flow of liquids in surface grooves. Langmuir 1996, 12: 555-565.

[29] Li MZ. Research on thermal cycling performance and CMAS corrosion behavior of $\mathrm{GdPO}_{4}$ thermal barrier coating. Tianjin University, 2018.

[30] El Ouenzerfi R, Panczer G, Goutaudier C, et al. Relationships between structural and luminescence properties in $\mathrm{Eu}^{3+}$-doped oxyphosphate-silicate apatite $\mathrm{Ca}_{2+x} \mathrm{La}_{8-x}\left(\mathrm{SiO}_{4}\right)_{6-x}$ $\left(\mathrm{PO}_{4}\right)_{x} \mathrm{O}_{2}$. Opt Mater 2001, 16: 301-310.

[31] Krämer S, Yang J, Levi CG. Infiltration-inhibiting reaction of gadolinium zirconate thermal barrier coatings with CMAS melts. J Am Ceram Soc 2008, 91: 576-583.

[32] Wang XY, Zhang L, Zhang ZJ, et al. Effects of $\mathrm{pH}$ value on growth morphology of $\mathrm{LaPO}_{4}$ nanocrystals: Investigated from experiment and theoretical calculations. Appl Phys A 2016, 122: 508.

[33] Li BT, Chen Z, Zheng HZ, et al. Wetting mechanism of CMAS melt on YSZ surface at high temperature: Firstprinciples calculation. Appl Surf Sci 2019, 483: 811-818.

Open Access This article is licensed under a Creative Commons Attribution 4.0 International License, which permits use, sharing, adaptation, distribution and reproduction in any medium or format, as long as you give appropriate credit to the original author(s) and the source, provide a link to the Creative Commons licence, and indicate if changes were made.

The images or other third party material in this article are included in the article's Creative Commons licence, unless indicated otherwise in a credit line to the material. If material is not included in the article's Creative Commons licence and your intended use is not permitted by statutory regulation or exceeds the permitted use, you will need to obtain permission directly from the copyright holder.

To view a copy of this licence, visit http://creativecommons.org/licenses/by/4.0/. 